\title{
System Design and Optimisation Study on a Novel CCHP System Integrated with a Hybrid Energy Storage System and an ORC
}

\author{
Jie Ji $\mathbb{D}^{1},{ }^{1}$ Zujun Ding $\left(\mathbb{D},{ }^{1}\right.$ Xin Xia $\mathbb{D}^{1},{ }^{1}$ Yeqin Wang, ${ }^{1}$ Hui Huang, ${ }^{1}$ Chu Zhang, ${ }^{1}$ Tian Peng $\left(\mathbb{D},{ }^{1}\right.$ \\ Xiaolu Wang, ${ }^{1}$ Muhammad Shahzad Nazir, ${ }^{1}$ Yue Zhang, ${ }^{1}$ Baolian Liu, ${ }^{1}$ Xiaoying Jia, \\ Ruisheng $\mathrm{Li}^{2}{ }^{2}$ and Yaodong Wang ${ }^{3}$ \\ ${ }^{1}$ Huaiyin Institute of Technology, Huaiyin, Jiangsu 223002, China \\ ${ }^{2}$ Merz Court, Newcastle University, Newcastle upon Tyne NE1 7RU, UK \\ ${ }^{3}$ Energy Systems, Department of Engineering, Durham University, Durham DH1 3LE, UK
}

Correspondence should be addressed to Zujun Ding; 46768424@qq.com

Received 2 April 2020; Accepted 6 July 2020; Published 26 September 2020

Academic Editor: Marcin Mrugalski

Copyright (c) 2020 Jie Ji et al. This is an open access article distributed under the Creative Commons Attribution License, which permits unrestricted use, distribution, and reproduction in any medium, provided the original work is properly cited.

\begin{abstract}
For achieving higher energy transferring efficiency from the resources to the load, the Combined Cooling, Heating, and Power (CCHP) systems have been widely researched and applied as an efficient approach. The key idea of this study is designing a novel structure of a hybrid CCHP system and evaluating its performance. In this research, there is a hybrid energy storage unit enhancing the whole system's operation flexibility while supplying cooling, heating, and power. An ORC system is integrated into the CCHP system which takes responsibility of absorbing the low-temperature heat source for electricity generation. There are a few research studies focusing on the CCHP systems' performance with this structure. In order to evaluate the integrated system's performance, investigation and optimisation work has been conducted with the approaches of experimental studies and modelling simulation. The integrated system's configuration, the model building process of several key components, the optimisation method, and the case studies are discussed and analysed in this study. The design of the integrated system and the control strategy are displayed in detail. Several sets of dynamic energy demand profiles are selected to evaluate the performance of the integrated system. The simulation study of the system supplying selected scenarios of loads is conducted. A comprehensive evaluation report indicates that the system's efficiency during each study process differs while supplying different loads. The results include the power supplied by each component, the energy consumed by each type of load, and the efficiency improvements. It is found that the integrated system fully satisfies the selected domestic loads and various selected scenarios of loads with high efficiency. Compared to conventional power plants or CHP systems, the system efficiency enhancement comes from higher amount of recovery waste heat. Especially, the ORC system can absorb the low-temperature heat source for electricity generation. Compared to the original following electrical load (FEL) control strategy, the optimisation process brings overall efficiency improvements. The system's overall efficiency was increased by from 3\%,3.18\%, 2.85\%, $17.11 \%, 8.89 \%$, and $21.7 \%$ in the second case studies. Through the whole study, the main challenge lies within the design and the energy management of the integrated system.
\end{abstract}

\section{Introduction}

The combined cooling, heating, and power CCHP systems have the function of recovery of the waste heat to supply cooling and heat to satisfy the electrical power demand simultaneously [1]. By the other means, the trigeneration systems have advantages of high-efficiency energy transferring compared to the conventional energy systems [2].
The features of high efficiency and low emission which likely contribute significantly to reduce emissions draw a lot of attention in the recent decades.

Utilizing the recovered heat is a core technology for the CCHP systems. A general point about the CCHP systems' capacity is that the power rate lower than $1 \mathrm{MWe}$ is regarded as small-scale applications. Systems with smaller capacity are called small-scale or microscale CCHP systems [3]. The 
small-scale and microscale CCHP systems are a popular topic as the household energy demand or small commercial applications are suitable loads for this kind of distributed energy systems and such remote loads cannot get a highefficiency power supply in common case [4]. Adollahi discusses a multiobjective optimisation on the residential smallscale CCHP system. In this CCHP system, the energy efficiency, the total installation cost rate, and the cost rate of the environment are optimised simultaneously [5]. Another CCHP system designed for small-sale applications is presented by Maraver aiming at improving the use of biomass resources and distributed generation. In that research, the concepts of artificial thermal efficiency and the primary energy saving ratio are introduced to evaluate the designed system. The results of the research show that a small-scale CCHP plant based on biomass combustion is an efficient energy generation system [6].

A multienergy products system normally needs an advanced control system [7]. The control strategy of the complex energy system is also an area many recent research studies focus on [8]. The most popular and reasonable operation strategy for CCHP systems is following thermal load (FTL) [9] and following electrical load (FEL) [10]. A domestic CHP system which is also integrated with an electrical energy storage unit is using the FEL strategy to offer electricity and heat to the demands. The final results show that, with the support of the FEL strategy, the integrated CHP system has much higher efficiency compared to conventional off-grid CHP systems. For the most popular FTL and FEL control strategy, applying either of the strategies often causes power surplus which brings an efficiency reduction [11]. In a similar system, a dynamic programming operation strategy was developed to distribute the generated energy which brings $19 \%$ efficiency improvement [12]. For solving this problem, integration of energy storage units is proposed to improve part load efficiency and operation flexibility [13]. A distributed power generation system (DPGS) with an electric energy storage (EES) system has a similar idea with the current study. The results show that the DPGS-EES system was working properly to meet the demand [14]. There is an attempt of integrating the hybrid electrical energy storage with a domestic CHP system. The results show that Lang presents a CCHP system with the thermal energy storage system driven by a microturbine. The results of the system's operation show that the primary energy consumption of that CCHP system is significantly lower than that of conventional separate production systems [15]. A hybrid photovoltaic-trigeneration system is presented by Amir which contains batteries in its system structure. The batteries store the electrical energy from the solar panels and support the energy supplying of the system. The overall efficiency is demonstrated to be higher, and less emissions are generated compared to the current combination of centralized power plants and household heating technologies [16]. Among all the energy storage technologies, the supercapacitors have the ability to accommodate a large amount of energy in a short time. It has a similar operation principle and function with batteries [17]. When a distributed energy system has a dynamic electrical load, supercapacitors are suitable to be integrated in because of its high-power density. A CHP system combined with hybrid electrical energy storage was presented and simulated by Chen et al. In that system, the hybrid electrical energy storage system which contains lead acid batteries and supercapacitors supported the system to satisfy the dynamic load with limited energy source with high efficiency [18]. Among all the attempts, a few systems successfully combine the traditional batteries and supercapacitors with the CCHP systems.

There is always mismatch between the energy supply and the demand, especially in the multipower products generation systems [19]. Lots of researchers have been working on this topic to avoid excess output of electricity or heat [20]. In the CCHP systems, the waste heat is recovered for improving the system's efficiency. Besides that, it is well proven in actual operational condition that there is a potential part of waste heat which can be further extracted and transferred to useful energy by the ORC systems [21]. The idea of combining the CCHP system with ORC has been tested by many former researches. Zare combines a geothermal-driven CCHP system with the ORC system. The ORC system is used to absorb part of system internal heat for higher power output [22]. In Wang's CCHP-ORC system, the fuel consumption is reduced [23]. The ORC systems have proven that part of low-temperature heat can be transferred to available electricity $[23,24]$.

The integrated system studied in this research combines the trigeneration system, a novel electricity storage system, and the ORC system. This new designed integrated system manages to meet the energy demand at high efficiency with its optimised operation strategy. The aim of this study is to establish a feasible solution to tackle the challenge, i.e., to investigate and develop an integrated system of combined trigeneration, energy storage, and ORC to generate multienergy products (power, heat, and cooling) with high efficiency; to reduce the energy consumption; and reduce the carbon emissions from the stand-alone systems. This system structure shows its novelty for integrating the core components- a CCHP system, a hybrid energy storage unit, and an ORC system. Combining the ORC system and energy storage unit (including supercapacitors) with the trigeneration system is the very first attempt. The research focuses on building this integrated system and optimisation of the system's operation. Simulation on this integrated system is built from the results of the experimental tests. The optimisation process is the main content of this article.

The detailed objectives of the research are as follows:

(1) Investigating the state of the art of current energy systems; considering what types of the energy system and which technologies can reach the aim of the research; and selecting the energy system and technologies for the study

(2) Selecting the case study of a stand-alone user demand; designing an integrated system which can meet the demand; and setting up computational 
models to simulate and evaluate the system's performance

(3) Carrying the optimisation process on the system's operation on several scenarios; displaying the best/ optimisation of the system's performance

The main contribution of this article includes the following:

(1) Designing a novel structure of the hybrid CCHP system and evaluating its performance

(2) Investigating the control approach for the multiobject energy system and obtaining an optimised result

With this newly designed CCHP system integrated with hybrid energy storage units and an ORC system, the system should have the ability to satisfy the electricity, heating, and cooling demand simultaneously with high efficiency.

\section{System Configuration}

2.1. System Design. The schematic diagram of these components is displayed in the Figure 1 where the energyproducing lines are distinguished by different colours. This integrated system combines the key components to supply multitype of energy products.

The CCHP system includes a diesel engine, a generator, a heat recovery system, and an absorption chiller. The engine drives the generator to supply electricity. The generator operates with the energy storage units to supply energy for the electrical load. The electricity generated from the ORC is an auxiliary electricity source for this system (electricity from ORC is only available when the engine is operating). The function of electricity supplying of the system is given the highest priority in the system design because of the frequent changing electricity demand. The heat recovery system collects and transfers energy from waste heat to satisfy the heating demand and cooling demand. Part of the low-temperature heat is absorbed by the ORC system. When the recovery waste heat is not sufficient, the electricity is used to support the heating supply or cooling supply. The adsorption refrigerator produces most of the cooling energy. Cooling demand has lower priority than the other two energy demands.

2.2. Size of the System. This study aims at building a microCCHP system and supplying according loads. Specifications about the diesel engine and the generator are shown in the Table 1 . The power rate of the engine is $8.8 \mathrm{~kW}$, and the output rate of the generator is $6.5 \mathrm{~kW}$. Except the generated electricity, part of available power from the gas emissions and coolant water of the engine is also considered as a power source to the integrated system. The theoretical full load peak power output of the system including electricity, heating, and cooling is estimated $17.6 \mathrm{~kW}$. Power demand under $13 \mathrm{~kW}$ is a reasonable range for this integrated system to supply. The peak power demand of the loads selected in this study is around $10 \mathrm{~kW}$.
2.3. Control Strategy. Implementation of the operation strategies aims at achieving a high efficiency to supply the load. In the control strategies which have been conducted and tested, the most popular two investigated controlling strategies for similar systems are following the thermal load (FTL) and following the electric load (FEL) [25]. The selected load lasts for 24 hours. During this period, the power demand has an unpredictable swing according to different human activities. Therefore, the control strategy of this integrated system applies FEL. The operation logical diagram is displayed in Figure 2. Supplying the electrical energy demand has the highest priority. The allocation of electricity storing and consumption depends on the power demand of the load when the engine is operating. When the electrical demand is fully satisfied, the waste heat recovery system supplies energy for the thermal part and cooling part. The thermal load is satisfied by the recovered waste heat. The cooling energy is also supplied by the adsorption chiller which also extracts the recovered waste heat as energy source.

Based on the amount of energy demand, the integrated system is designed to operate as several states. The electricity demand has the highest priority, when the electricity demand is not fully supplied, and the ORC system uses the recovered heat and transfers them to electricity (when the engine is operating). When the electricity demand is fully supplied, the integrated system supplied thermal energy secondly. The supplying of cooling energy has the lowest priority. When the thermal energy generated is not sufficient for the load, the energy stored in the energy storage system supports the generation of thermal energy.

2.4. Optimisation Principles of the System's Operation. The original strategy makes the engine to operate with a flexible range of load. A similar optimisation process is applied in the former research [26]. The optimisation process shown in this section aims at reaching the system's maximum efficiency by making the engine to work at maximum power.

The engine in the system is the prime mover. It transfers the energy in the fuel into the system with certain efficiency.

$$
P_{\text {fuel }} \cdot \eta_{\text {engine }}=P_{\text {engine }} \text {. }
$$

The energy storage units contain the supercapacitors and the batteries. The power of the energy storage equals the summation of the two components' power.

$$
P_{s}=P_{\mathrm{SU}}+P_{\mathrm{BT}} .
$$

The equation expresses the recovery energy amount from the engine.

$$
P_{R}=P_{\text {fuel }} \cdot \eta_{\text {recovery }} .
$$

Part of the recovery energy is used to support the operation of the ORC.

$$
P_{\mathrm{ORC}}=P_{R}(1-\alpha-\beta) .
$$

When the generator is operating, the energy using to supply the load consists of the power of generator, energy 


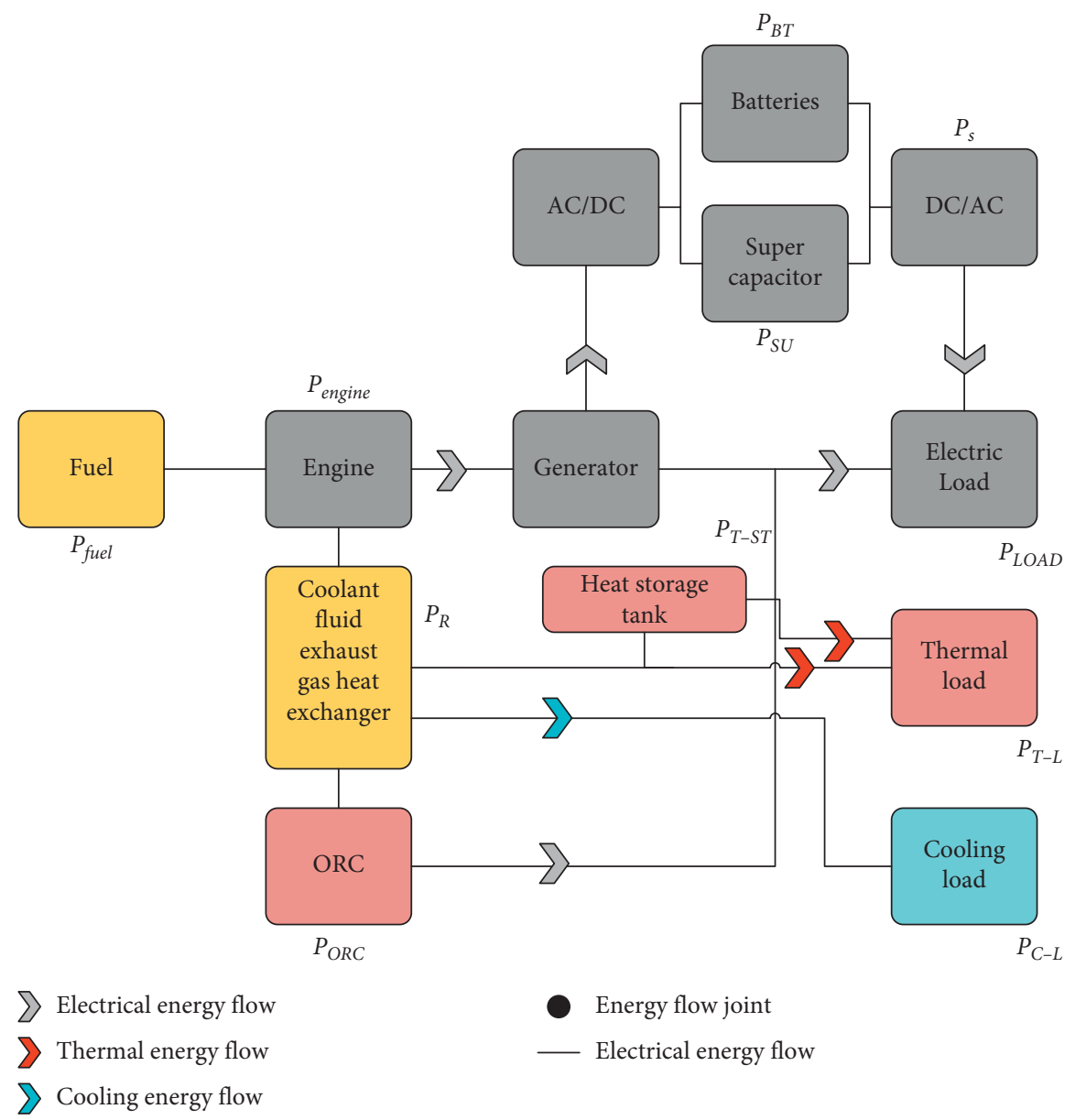

Figure 1: System design.

TABLE 1: Information of the engine and generator used in this study.

\begin{tabular}{|c|c|c|c|}
\hline \multirow{13}{*}{ Engine } & YANMAR & & TF $120 \mathrm{M}$ \\
\hline & Type & & Horizontal water-cooled, 4-cycle diesel engine \\
\hline & Bore $x$ stroke & $\mathrm{mm}$ & $92 \times 96$ \\
\hline & Displacement & Liters & 0.638 \\
\hline & Cont. output & kW (hp) & $7.7(10.5)$ \\
\hline & Rated output & $\mathrm{kW}(\mathrm{hp})$ & $8.8(12)$ \\
\hline & Revolutions & $\mathrm{rpm}$ & 2400 \\
\hline & Starting system & & Hand start \\
\hline & Cooling system & & Radiator \\
\hline & Lubricating system & & Fully sealed forced lubrication with a trochoid pump and hydraulic regulator valve \\
\hline & Combustion system & & Direct injection \\
\hline & Fuel consumption & lit./h & 2.8 \\
\hline & Fuel tank capacity & Liters & 11 \\
\hline \multirow{9}{*}{ Generator set } & \multirow[t]{2}{*}{ Capacity } & $\mathrm{kVA}$ & 6.5 \\
\hline & & $\mathrm{kW}$ & 6.5 \\
\hline & Frequency & $\mathrm{Hz}$ & Available in either $50 \mathrm{~Hz}$ or $60 \mathrm{~Hz}$ \\
\hline & Revolutions & rpm & 3000 for $50 \mathrm{~Hz} / 3600$ for $60 \mathrm{~Hz}$ \\
\hline & No. of phases & & Single phase \\
\hline & Power factor & & 1 \\
\hline & Excitation system & & Brushless, self-excitation system \\
\hline & Drive system & & V-belt derive \\
\hline & Voltage (standard) & $\mathrm{V}$ & 220 \\
\hline
\end{tabular}




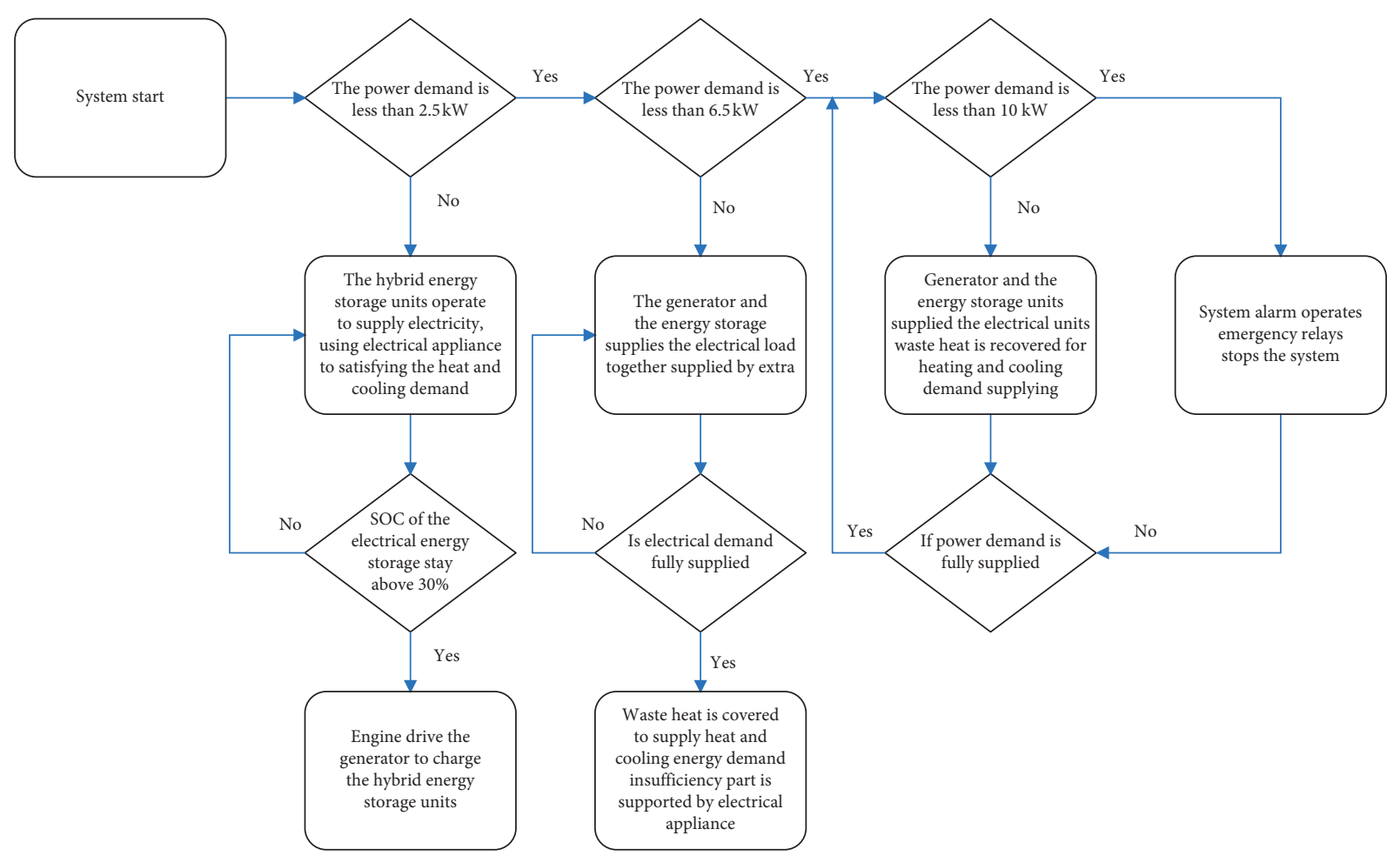

Figure 2: Control strategy of the system.

storage system, and the electric power output from the ORC. During the system's operation, the recovery energy is used to satisfy the heat demand. The thermal storage unit reserves part of the excessive energy.

$$
\begin{aligned}
P_{\mathrm{LOAD}} & =P_{\mathrm{GE}}+P_{S}+P_{\mathrm{OE}}, \\
P_{R} \cdot \alpha+P_{T-\mathrm{SL}} & =P_{T-L}, \\
P_{R} \cdot \beta \cdot \eta_{C} & =P_{\mathrm{C}-L} .
\end{aligned}
$$

When the generator is not operating, the energy storage units support the electric loads. Because of lacking recovery energy, the heating load and the cooling load are supplied by the energy stored in the storage units.

$$
\begin{aligned}
P_{\mathrm{LOAD}} & =P_{S}, \\
P_{\mathrm{ET}}+P_{T-\mathrm{SL}} & =P_{T-L}, \\
P_{R} \cdot \beta & =P_{\mathrm{EC}} .
\end{aligned}
$$

Supposing that the system's operation follows the electric load (FEL), the optimisation of the system aims at minimizing the engine's operation time. From calculating the difference between the minimum engine operation time and the compensational engine operation time, a better operation for the integrated system can be obtained.

$$
\begin{aligned}
t_{\min }^{\prime} & =\frac{\int_{0}^{t e} P_{\text {engine }}(t) \mathrm{d} t}{P_{\text {engine }}(\max )}, \\
t^{\prime} & =t_{\min }^{\prime}-t_{\min }, \\
\int_{0}^{t^{\prime}} P_{\mathrm{OE}}(t) \mathrm{d} t & =P_{\text {engine }}(\max ) \cdot t^{\prime} .
\end{aligned}
$$

2.4.1. Limiting Conditions. There are a few restrictive conditions in the optimisation process for guaranteeing sufficient power for the load. For ensuring the batteries' lifespan, the state of charge of the batteries is limited within the rage from $40 \%$ to $100 \%$. At the same time, the power supplied by the system must be equal or higher than the power demand. The thermal energy stored in the storage units is required to fulfill the thermal load and the cooling load. The recovery thermal energy is allocated to three parts which are responsible for the thermal storage, heating demand, and cooling demand, respectively.

$$
\left\{\begin{array}{l}
40 \%<\operatorname{SOC}(t)<100 \%, \\
P_{\mathrm{GE}}+P_{S}+P_{\mathrm{OE}} \geq P_{\mathrm{LOAD}}, \\
P_{R} \cdot \alpha+P_{T-S \mathrm{~L}} \geq P_{T-L}, \\
P_{R} \cdot \beta \geq P_{\mathrm{C}-L} .
\end{array}\right.
$$

The saved energy is expressed by the following equation. The energy saving is

$$
Q_{\text {saving }}=\int_{0}^{\text {te }} \frac{P_{\text {engine }}(t)}{\eta_{\text {engine }}} \mathrm{d} t-P_{\text {engine }}(\max ) t_{\text {min }} .
$$

\section{Model Building of the System}

The principle of building the components is introduced in this section where the process of model building is expressed. The evaluation work and the optimisation process are completed by the simulation models in the Matlab software environment. The accuracy of the build 
components is guaranteed by fitting the performance of the components with their experimental tests results.

3.1. Generator of the System. The electricity generation applied in this project is a diesel engine. Equation (16) describes the mathematical model of the engine.

In the equation,

$$
\left\{\begin{array}{l}
T_{d} \Omega=E I_{A}, \\
E=K \varphi \Omega, \\
T_{d}=K \varphi, \\
P=T_{d} \Omega \times \eta=E I_{A} \times \eta .
\end{array}\right.
$$

The engine transfers the chemical energy to mechanical energy and, then, to electricity. Model for this part is built in Matlab software. Using the corresponding parameters, the recovered heat rate is also given in Table 2.

From the simulation results of the engine's model, the engine's electrical power output and the recovery heat simulation have error less than $1.42 \%$. These results indicate that the model can simulate the operation performance of the engine with a high accuracy.

3.2. Heat Recovery System. The model of the waste heat recovery module is based on the experimental results given by a former swan researcher. In the research of the biofuel microtrigeneration system, a previous researcher Hongdong tested the engine with 5 types of oil which are shown in the Figure 3 [27]. After fitting curve with the rests results, the heat recovery rate from gas oil's burning is modelled.

The heat recovery system is simulated as a black box using a performance curve to fit the experimental results. There are five operation points which are $10 \%, 25 \%, 50,75 \%$, and $100 \%$ load. The available waste heat and the recovered heat energy have a linear relationship based on curve analysis, and the mathematical model is shown by the following equations:

$$
P_{r}=P_{\text {engine }} \times 0.364+0.9676 .
$$

Figure 4 shows the comparison of test results and the simulation under different load conditions.

Based on the control strategy of this integrated system, most of the recovery system's operations are settled when the engine is loaded over $60 \%$. It indicates that the error of the recovery system's model is around $0.2 \%$ to $1.75 \%$.

3.3. Cooling Generation. In this integrated system, the chiller part consists of an adsorption chiller and the cooling generation appliance. The cooling generation is considered in two situations: 1 , when the engine is working, the adsorption chiller absorbed the recovered waste heat to generate cooling energy; 2, when the engine is off, the cooling is transferred from the electrical appliance. The cooling power out is shown in the following formula:

$$
\left\{\begin{array}{l}
\text { When the engine is on: } P_{C-L}=\left[P_{R} \cdot \beta\right] \cdot \eta_{C}, \\
\text { When the engine is off: } P_{C-L}=\left[P_{\text {engine }}-P_{\mathrm{SU}}-P_{\mathrm{BT}}-P_{E-L}\right] \cdot \eta_{E-C} .
\end{array}\right.
$$

3.4. Hybrid Energy Storage System. The power requirement of the integrated system is a variable during the different times of the day. For supplying reliable energy, the integrated system combines the hybrid energy storage system as its energy back up to make up for the disadvantages of a distributed system. The hybrid energy storage units consist of the lead acid batteries and the supercapacitors in this research.

For optimal utilization of the energy stored in the energy storage units, the size of the batteries and the supercapacitors is calculated and selected.

3.4.1. Battery. The batteries have high energy density. It is responsible for supplying enough electricity to load. The formula which expresses the operation of the lead acid batteries using state of charge as its variable is listed as follows [27]:

$$
\operatorname{SOC}(t+1)=\operatorname{SOC}(t)-\operatorname{SOC}(t) \cdot \sigma+\frac{I_{\mathrm{Bat}}(t) \cdot \Delta t \cdot \eta_{\mathrm{Bat}}}{C_{\mathrm{Bat}}(t)} .
$$

In the equation, $\sigma$ is the self-discharge rate of the battery whose value is set as $0.2 \%$ per day. $C_{\mathrm{Bat}}$ is the capacity of the battery.
The detail parameters of the batteries and the supercapacitor are shown in Table 3.

3.4.2. Supercapacitor. In this study, the supercapacitors are selected for satisfying dynamic changing power demand. The specifications of the supercapacitor are listed in Table 4 . The formula of the supercapacitor is displayed in the following equation:

$$
\left\{\begin{array}{l}
P_{\mathrm{SU}}=\frac{1}{2} C \cdot U^{2}=\frac{1}{2} \varepsilon \cdot \frac{S}{d U^{2}}, \\
\varepsilon=\frac{2 W}{V E^{2}} .
\end{array}\right.
$$

Here, $\varepsilon$ is the dielectric constant, $E$ is the electric field intensity, and $C$ is the volume of the supercapacitor.

\subsection{ORC System}

3.5.1. Working Fluid Selection. The ORC system integrated in is designed for low-grade heat recovery. The ORC system is driven by the waste heat absorbed from the engine. Several key factors have the most significance on the ORC's 
TABLe 2: Energy output in the simulation.

\begin{tabular}{lcccc}
\hline Load of the engine (\%) & Engine efficiency (\%) & Error (\%) & Recovery rate simulation (\%) & Error (\%) \\
\hline 0 & 0 & 0 & 0 & 35.36 \\
10 & 7.8 & 1.13 & 35.38 & 0.079 \\
25 & 16.36 & 0.36 & 35.39 & 0.025 \\
50 & 24.3 & 0.41 & 35.41 & 0.027 \\
75 & 27.53 & 0.82 & 35.44 & 0.138 \\
100 & 28.5 & 1.42 & 0.137 \\
\hline
\end{tabular}

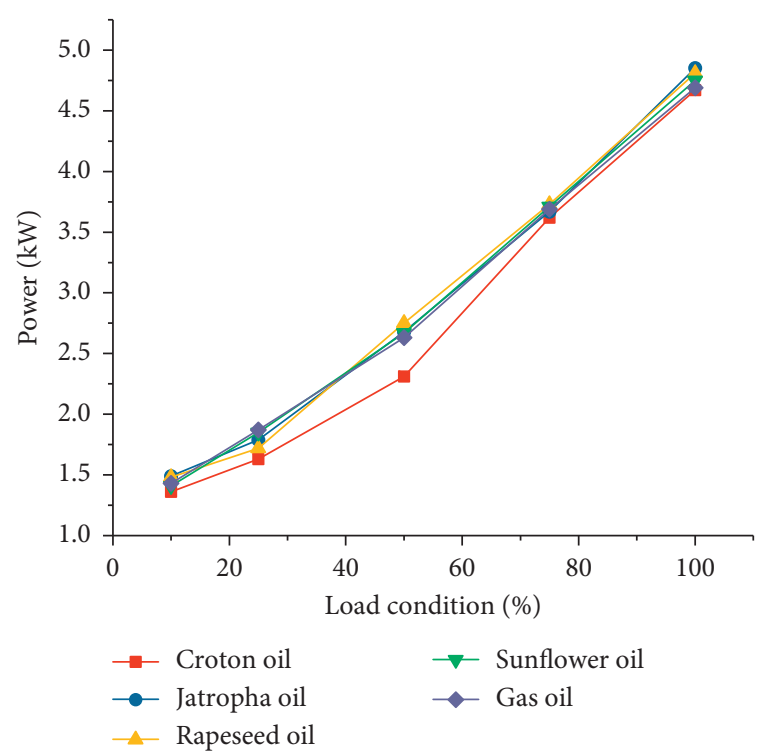

FIgURE 3: Recovered exhaust gas heat for cogeneration [27].

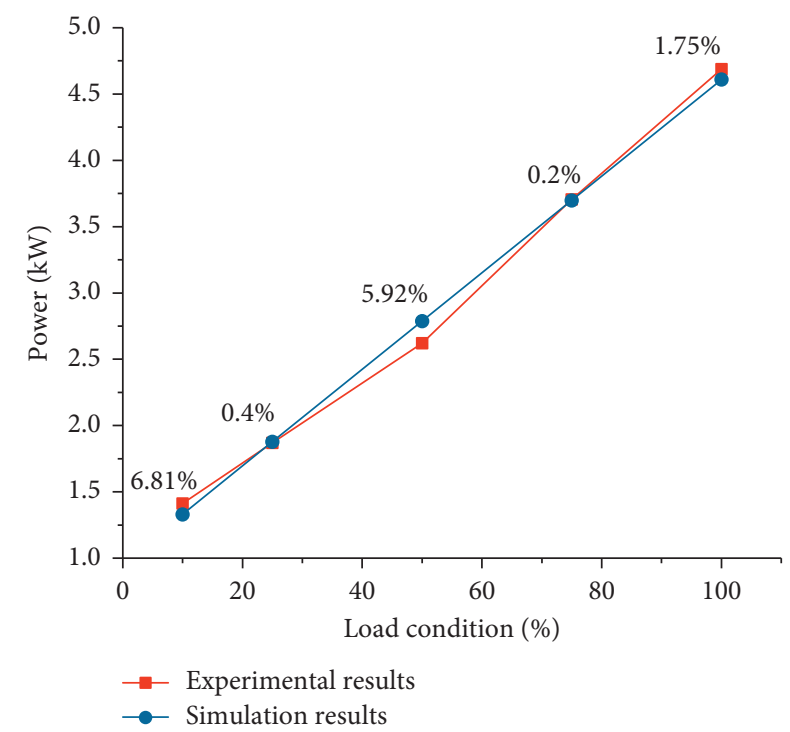

FIGURE 4: Simulation results comparing with the experimental results.

performance which are source temperature, working medium, safety issues, and problem of degradation. For all the working fluids, the ODP, GWP, R134a, and R245fa are appropriate to be applied in a small-scale ORC [28]. R123a has ozone depletion potential which leads to aggravate the global warming. The R245fa has similar chemical and physical
TABle 3: Specifications of the lead acid batteries.

\begin{tabular}{lc}
\hline Parameter & Mean value \\
\hline Nominal capacity & $200 \mathrm{Ah}$ \\
Nominal voltage & $12 \mathrm{~V} \mathrm{DC}$ \\
Depth of discharge & $40 \%$ \\
Maximum state of charge & $100 \%$ \\
Minimum state of charge & $40 \%$ \\
Efficiency & $85-95 \%$ \\
Self-discharge & $20 \% /$ day \\
Temperature coefficient & $0.6 \% /{ }^{\circ} \mathrm{C}$ \\
Lifetime & 5 years \\
\hline
\end{tabular}

TABle 4: Parameters of the supercapacitor.

\begin{tabular}{lc}
\hline Parameter & Mean value \\
\hline Capacity & $63 \mathrm{~F}$ \\
Voltage & $125 \mathrm{~V} \mathrm{DC}$ \\
Resistance & $18 \mathrm{~m} \Omega$ \\
Temperature & $-40-60$ \\
Life span & 100,000 hours \\
End of life reduction of capacity & $20 \%$ \\
Maximum current & $150 \mathrm{~A}$ \\
Maximum peak current & $750 \mathrm{~A}$ \\
Self-discharge & $50 \% / 30$ days \\
\hline
\end{tabular}

properties as a good candidate for the ORC system. It also has zero-ozone depletion potential, low toxicity, no flammability, and applicable critical temperature and pressure. Therefore, $\mathrm{R} 245 \mathrm{fa}$ is selected as the working fluid in the ORC system. An ORC system contains several basic components: a heat source, evaporator, turbine, condenser, and pump.

The waste heat recovered by this system consists of heat from the exhaust gas and the coolant of the engine. For achieving the highest efficiency during the heat transferring process, the working fluid is selected as R245fa. This working fluid has lower ebullition temperature which has lower evaporating temperature than water. Figure 5 shows the T-S diagram of R245fa in an ORC cycle. The R245fa is pumped to the evaporator, and its entropy and temperature are slightly increased before entering the evaporator. When the working fluid is leaving the evaporator, the entropy of R245fa increases compared to its state before. After that, the R245fa goes into the turbine, and the temperature decreases when its entropy slightly increases.

3.5.2. ORC Model Building. Power output of the ORC system is modelled in this study, and some similar ORC system equations are also applied in the author's former research [26]: 


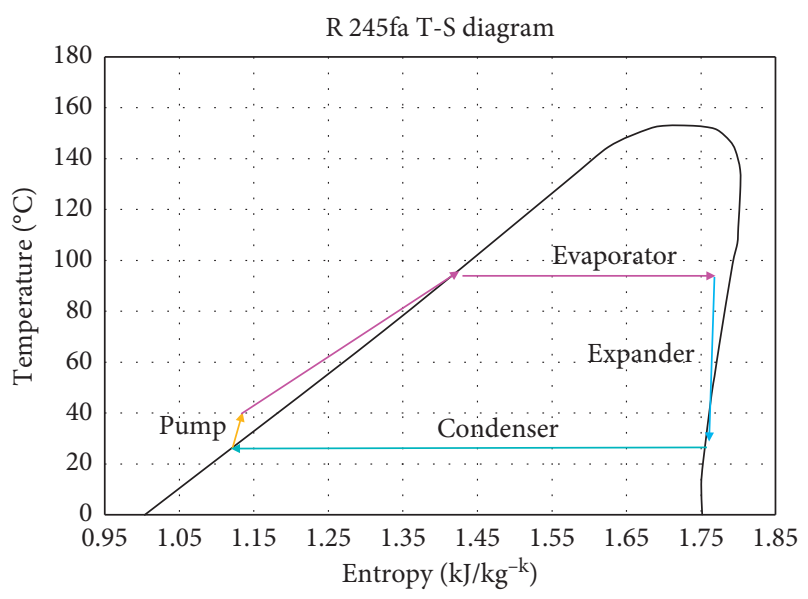

FIgURE 5: T-S diagram of R245fa.

$$
\left\{\begin{array}{l}
W_{p}=m_{\mathrm{orc}}\left(h_{2}-h_{1}\right)=\frac{m_{\mathrm{ORC}}\left(h_{2 s}-h_{1}\right)}{\eta_{p}}, \\
\eta_{p}=\frac{h_{2 s}-h_{1}}{h_{2}-h_{1}}
\end{array}\right.
$$

where $W_{p}$ is the pump's power; $m_{\mathrm{ORC}}$ is the mass flow rate; $\eta_{p}$ is the pump's efficiency; and $h_{2}, h_{1}$ are the inlet and outlet fluid enthalpies.

$$
Q_{\text {ep }}=Q_{\mathrm{ro}} \cdot \xi=m_{\text {orc }}\left(h_{3}-h_{2}\right) .
$$

Heat accepted by the evaporator is $Q_{\mathrm{ep}} ; \xi$ is the evaporator effectiveness; $Q_{\text {ro }}$ is the recovered thermal energy; $h_{2}$ are the enthalpies of the working fluid at the outlet of the evaporator.

The process of the condenser is expressed by the following equation:

$$
Q_{\mathrm{cd}}=m_{\mathrm{orc}}\left(h_{1}-h_{4}\right) .
$$

In the equation, $Q_{c d}$ is the heat output of the condenser and h4 is the working fluid enthalpy at the outlet of the turbine.

The turbine power output is

$$
\left\{\begin{array}{l}
W_{t}=m_{\text {orc }}\left(h_{3}-h_{4}\right)=m_{\text {orc }}\left(h_{3}-h_{2}\right) \eta_{t}, \\
\eta_{t}=\frac{h_{3}-h_{4}}{h_{3}-h_{4 s}} .
\end{array}\right.
$$

In the equation, $W_{t}$ is the turbine output power and $\eta_{t}$ is the isentropic efficiency of the turbine.

The ORC system's overall efficiency is

$$
\left\{\begin{array}{l}
\eta_{\mathrm{ORC}}=\frac{W_{t}-W_{p}}{Q_{\mathrm{ep}}}=\frac{\left(h_{3}-h_{4 s}\right) \eta_{t}-\left(h_{2 s}-h_{1}\right) \eta_{p}^{-1}}{h_{3}-h_{2}}, \\
W_{t}=Q_{\mathrm{ro}} \eta_{\mathrm{ORC}} \eta_{\mathrm{gen}},
\end{array}\right.
$$

where $\eta_{\mathrm{ORC}}$ is the efficiency of the ORC system.
The thermal dynamic module of the ORC system was developed by the researcher from the same group. More details can be found in this research [29]. In this study, a general efficiency module is applied to represent the ORC system's ability of transferring low-temperature waste heat.

\section{Case Study}

The case study includes two parts of evaluation work on the system performance. In the first case study, the system is required to supply multitype of energy to a dynamic changing domestic load. Simulation of supplying dynamic load with this system is performed in a former research [26]. However, in this article, the energy supplying of the supercapacitor is imported. It has higher accuracy and more realistic power response compared to the former research. Also, the selected domestic load includes new load from a summer day and a winter day separately. In the second case, the system is supplied to two sets of designed loads (six scenarios of load) in two seasons. This article evaluates the system's performance of supplying energy to load through the two case studies.

4.1. Case Study 1-High-Resolution Domestic Load Supplying Simulation. The case study shows the optimised operation of the integrated system meeting the power demand of a domestic load in two seasons. The integrated system is regulated to supply three energy products for two varying loads for 24 hours. The load targets selected in this case study show a seasonal difference on power demand.

In both simulations, the control strategy applies the optimised FEL power allocating strategy. Electricity demand gets the priority. The recovery heat is the available thermal energy collected from the system. Part of the recovered heat is utilised to supply cooling load. For household domestic cooling load, in this case, the cooling load is a refrigerator. The cooling load is simulated as a pulse-shape power demand. The optimisation for the operation is applied in the simulation which makes the operation time of the engine to be optimised to a minimum value.

4.1.1. Summer Day Case. The first simulation is a summer day load. The operation results are shown in Figure 6.

In Figure 7, wave A shows the power demand of the domestic load on a summer day. The simulation results show that the peak power demand is larger than the capacity of the system. Throughout the simulations, the system's capacity is expanded by \#\#\% with integrating the hybrid energy storage unit. Wave B shows the engine's operation. The engine is regulated to operate only at the peak power demand period. The supercapacitors respond to high-density power demand. In the wave D, it only operates when the power demand and power supplying have sudden change. The wave $\mathrm{C}$ shows the power supplied by batteries which support most of the power demand when the engine is not working. Part of lowtemperature waste heat is utilised by the ORC. This part of thermal energy transmitted to the ORC is converted to electricity which increases the energy utilisation efficiency. 


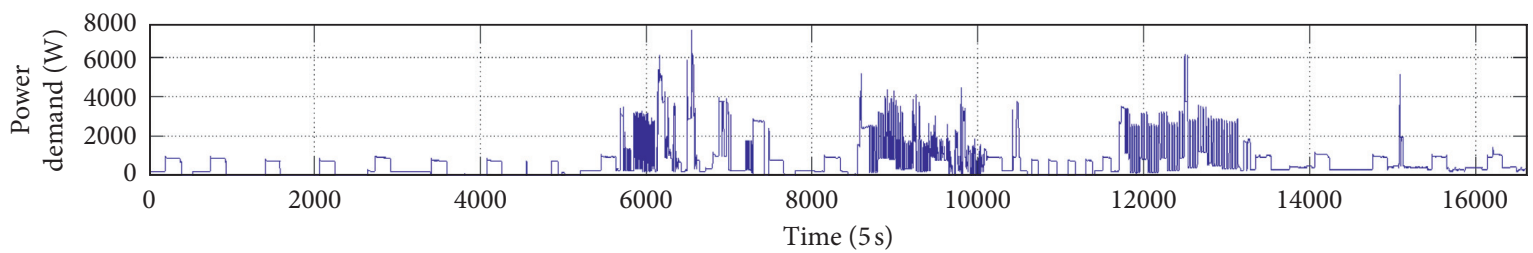

(a)

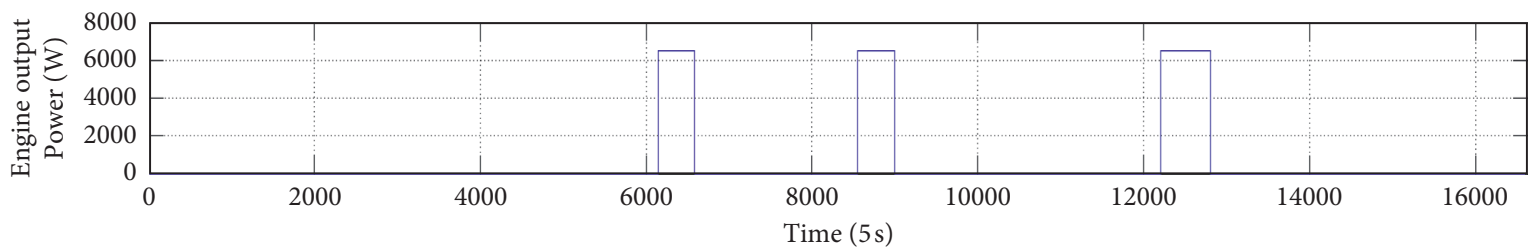

(b)

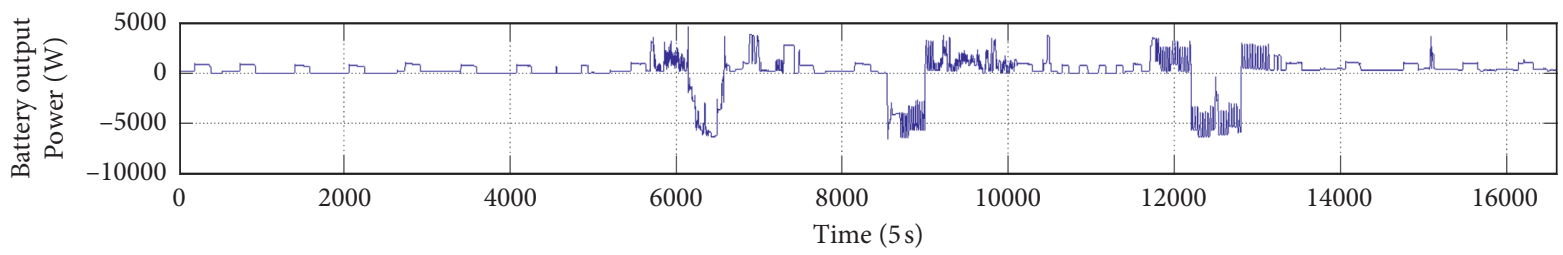

(c)

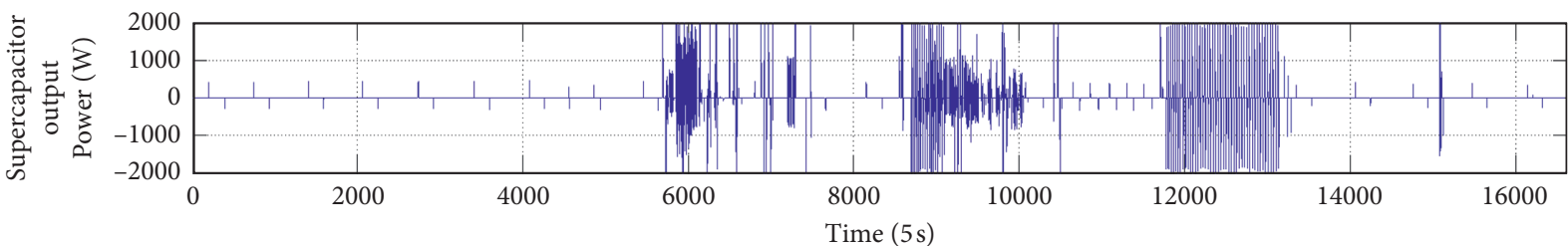

(d)

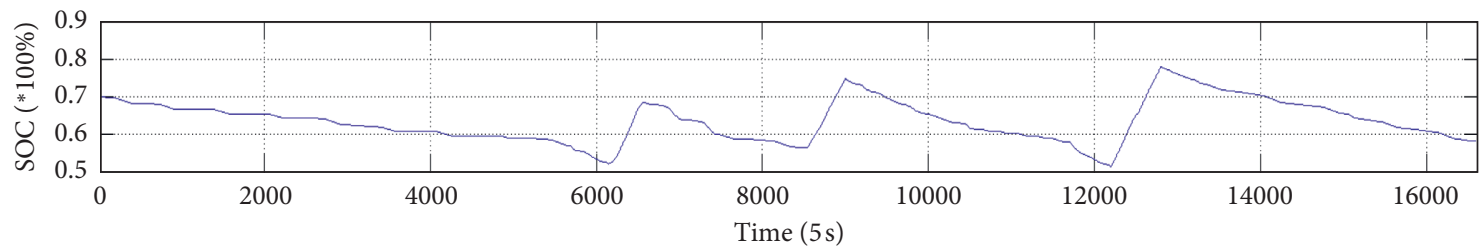

(e)

Figure 6: Five key parameters' values are recorded during the operation of the integrated system with label A, B, C, D, and E. They are, respectively, power demand, engine out, batteries operation, supercapacitors operation, and batteries' state of charge.

During the system's operation, when the engine is on, the ORC system utilizes the low-temperature waste heat and transfers them to available electricity. Based on the calculation of the results, the ORC contributes $2.3 \%$ electricity which brings a $2.37 \%$ increment to the electrical efficiency.

The recovered waste heat is used to supply the thermal demand. The specific thermal demand lacks data support. Therefore, the heat consumption is an estimated value based on the government's data and the household's energy consumption pattern [30]. The thermal energy generated is $4.6 \mathrm{kWh}$, and it is fully consumed to supply the thermal power demand. Most of the waste heat is recovered for heat demand. The thermal energy could be either stored in a heat tank or consumed directly to the load. The system is flexible to deal with the thermal energy. The simulation results show that $41 \%$ of available energy generated by the system is consumed for heat demand.
An absorption chiller is integrated in the system for satisfying cooling demand. The simulation results show that the cooling energy demand of the selected domestic load is $4.32 \mathrm{kWh}$. The cooling load is satisfied with $25.76 \%$ recovered heating energy.

4.1.2. Winter Load. In the simulation, the power source of the dynamic load consists of the engine and the waste heat recovery system. Wave A shows the power demand in Figure 7. The peak power demand cannot be satisfied by the engine alone. The hybrid energy storage unit operates as an auxiliary power supplier. In the simulation, energy storage units supplement the energy gap when the peak energy demand is larger than the rate power of engine. From the $C$ and D chart in Figure 7, large amount of electrical energy 


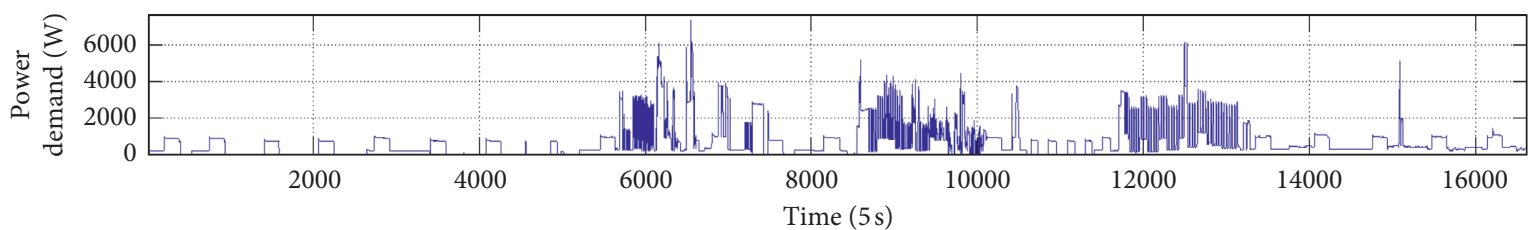

(a)

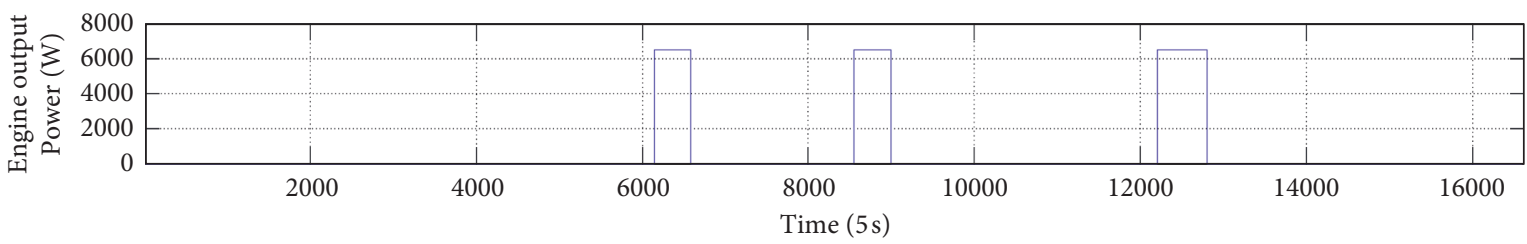

(b)

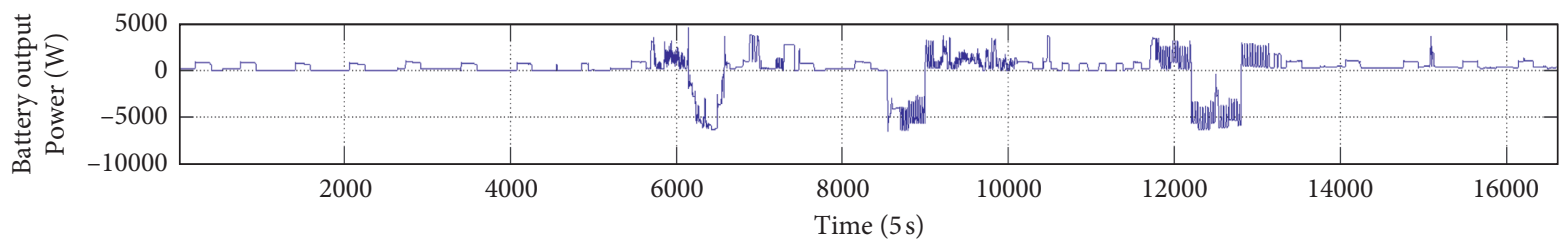

(c)

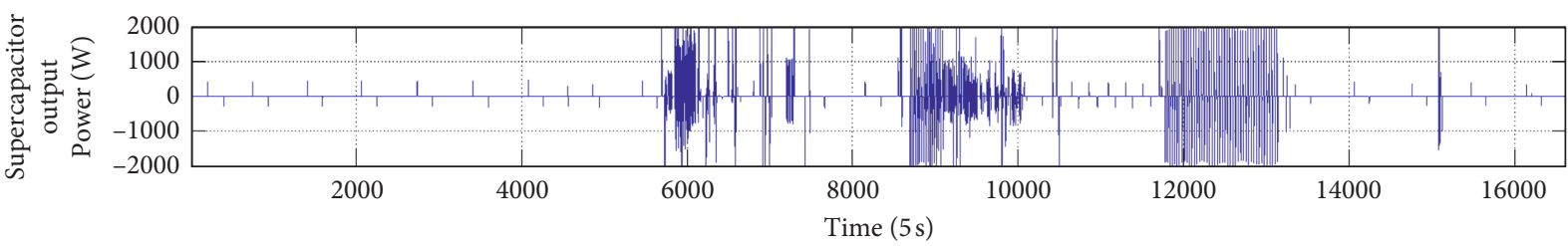

(d)

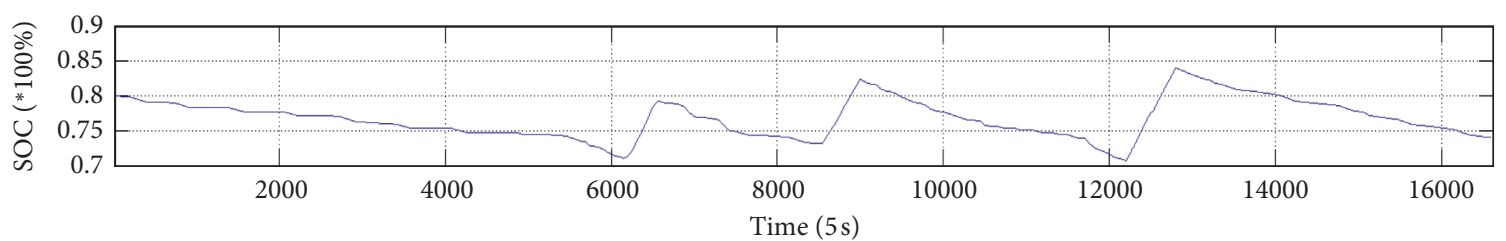

(e)

FiguRe 7: High-resolution simulation of the electrical energy supplying. (a) Electrical energy demand, (b) engine operation period, (c) batteries charging/discharging, (d) supercapacitor charging/discharging, and (e) the tracking of batteries' SOC.

was supplied by the batteries. The supercapacitors offered certain amount of energy in short time to fulfill the dynamic energy demand. Batteries' state of charge started from $80 \%$ and ends at $75 \%$ when the simulation ends.

The ORC system in this simulation produces $0.38 \mathrm{kWh}$ with the heat source recovered from the engine. The operation of the ORC system makes the trigeneration to have higher conversion rate on the waste heat energy. The electricity supplied by the ORC system takes up $2.4 \%$ of the total dynamic energy demand.

When the recovery heat is used to generate the electricity, the supplying of the heating demand is affected. In this case, as the efficiency of the recovery heat is higher than that of the ORC system, using certain amount of the recovery heat for electricity generation is under the condition that the heat demand is sufficiently supplied.
The heat demand is fulfilled by the recovered waste heat. The energy consumption is an estimated value which is in a reasonable range. The winter day load consumes $5.7 \mathrm{kWh}$ of heat. Most of the waste heat is used for thermal demand. Part of low-temperature waste heat is transmitted to the ORC for electricity conversion.

The cooling energy consumption is $0.62 \mathrm{kWh}$ in this case which is supplied with $2.7 \%$ recovered heat.

4.1.3. Summary of the Two Simulations. Information of the simulation results is displayed in the Table 5. In the two simulations, the energy demands are similar, which are $12.92 \mathrm{kWh}$ and $15.98 \mathrm{kWh}$, respectively. The energy demand of the target residential household has larger energy demand on a winter day than on a summer day. The engine is designed to operate at a shortest time to save energy. The integrated system 
TABLE 5: Key parameters displaying in the two set of simulations.

\begin{tabular}{lcc}
\hline & Summer day & Winter day \\
\hline Electrical energy demand & $12.92 \mathrm{kWh}$ & $15.98 \mathrm{kWh}$ \\
Energy supplied by the engine & $8.93 \mathrm{kWh}$ & $11 \mathrm{kWh}$ \\
Energy supplied by energy storage units & $3.68 \mathrm{kWh}$ & $4.59 \mathrm{kWh}$ \\
Electricity generated by the ORC system & $0.307 \mathrm{kWh}$ & $0.38 \mathrm{kWh}$ \\
Cooling energy demand & $4.32 \mathrm{kWh}$ & $0.62 \mathrm{kWh}$ \\
Heating demand* & $0.5 \mathrm{kWh}$ & $11 \%$ \\
System capacity enhancement & $27.4 \mathrm{kWh}$ & $5.7 \mathrm{kWh}$ \\
Energy consumed by the integrated system & $51.7 \mathrm{kWh}$ & $9.20 \%$ \\
Energy consumed by the separate system & $35.70 \%$ & $32.5 \mathrm{kWh}$ \\
Overall system efficiency & $47.00 \%$ & $53.92 \mathrm{kWh}$ \\
Efficiency enhancement compared to the separate system & $42.70 \%$ \\
\hline
\end{tabular}

* Part of thermal demand is supplied by electrical energy; that is why the thermal demand is smaller than normal residential cases.

satisfies the energy demand in both cases with the engine only operating at peak times. During the long off-peak time, the energy storage units supply the energy demand to the load. The ORC system transferred part of the waste heat energy to electricity. Limited by the heat source, the ORC system only generates a small amount of energy in these two cases. Although the ORC system enhances the system energy conversion ratio based on the results of the simulations, stable heat sources are necessary to have high economic efficiency. The electrical energy storage units are important in the simulation for expanding the system's capacity and enhancing the system's stability. With the energy storage units, the trigeneration system has the ability to supply load larger than the engine's rate power.

The amount of energy supplied by the engine was $8.93 \mathrm{kWh}$ in summer and $11 \mathrm{kWh}$ in winter. At the same time, the energy storage system only supplied $3.68 \mathrm{kWh}$ in summer and $4.59 \mathrm{kWh}$ in winter. It indicates that the energy storage system operates as auxiliary supplied in the electric part of the trigeneration system. Combined with the energy storage system, the energy supplying has little waste. The calculation results from the generator output and energy consumption, and the efficiency enhancements of the system are $47.00 \%$ and $39.70 \%$ in this case study. In the energy storage system, the lead batteries have high energy capacity compared to the supercapacitors. The maximum error of the two sets of simulation is $2.42 \%$ and $2.15 \%$. The average simulation errors are controlled in $1.85 \%$ and $1.79 \%$ in two sets, respectively.

4.2. Case Study 2- the Optimisation Process on Several Scenarios. Aiming at a comprehensive evaluation on the system's performance, various scenarios of load are designed for the system's performance assessment. The cooling, heating, and electricity loads on typical summer and winter days under different conditions are given in the Figures 8 and 9. In the simulation, the loads are designed to two groups. The first groups are loads for applications on typical summer days. The second groups are loads designed for applications on typical winter days. Unlike in domestic summer load and winter load, more complex requirements on the heating, cooling, and electricity are selected in this case study. The energy consumption in the scenarios come from the cooling, heating, and electricity loads profiles for industrial, commercial, and residential areas. The system simulated in this research has the power rate same as that in case study 1 . Using the system to supply a wide range of loads gives a comprehensive evaluation on the system's performance.

4.2.1. Optimisation Results of Case Study 2. Table 6 shows the simulation results of the system's optimised operation. Simulation results from the 6 scenarios give a comprehensive evaluation on the system' performance. Scenario one, scenario two, and scenario three simulate the system's operation on a summer day. The other three loads are designed for energy supplying in a winter day. The later three simulations investigate the system's performance on a winter day. During the system's simulation, the ORC system supplied about $10 \%$ of the electric energy demand. In the different scenarios, the energy storage units improve the system's capacity significantly. The minimum value was in scenario 5 (41.5\%), and the maximum value is in scenario $6-64.15 \%$. After the optimisation process, the system's engine operated with less time, and the system's overall efficiency is improved in each scenario. Based on the optimisation results, the engine is controlled to operate with full power rate with minimum time to satisfy the load.

Different from the previous simulation of the trigeneration system, short time of the engine's operation with full power rate improves the electric efficiency of the system. The optimisation process converts more energy to electricity from the fuel, and the higher electricity efficiency contributes to the system overall efficiency. In the first three scenarios, the overall efficiency is lower than that in the last three scenarios. The load on a typical summer day needs more cooling energy, which is the weak part of the system. The cooling energy in this system is transferred from the recovery heat. It limited the cooling energy conversion efficiency, which is the fundamental reason why the system's efficiency is low in the first three scenarios. In the last three scenarios, the system generated more heating and electricity which make the overall efficiency higher. 

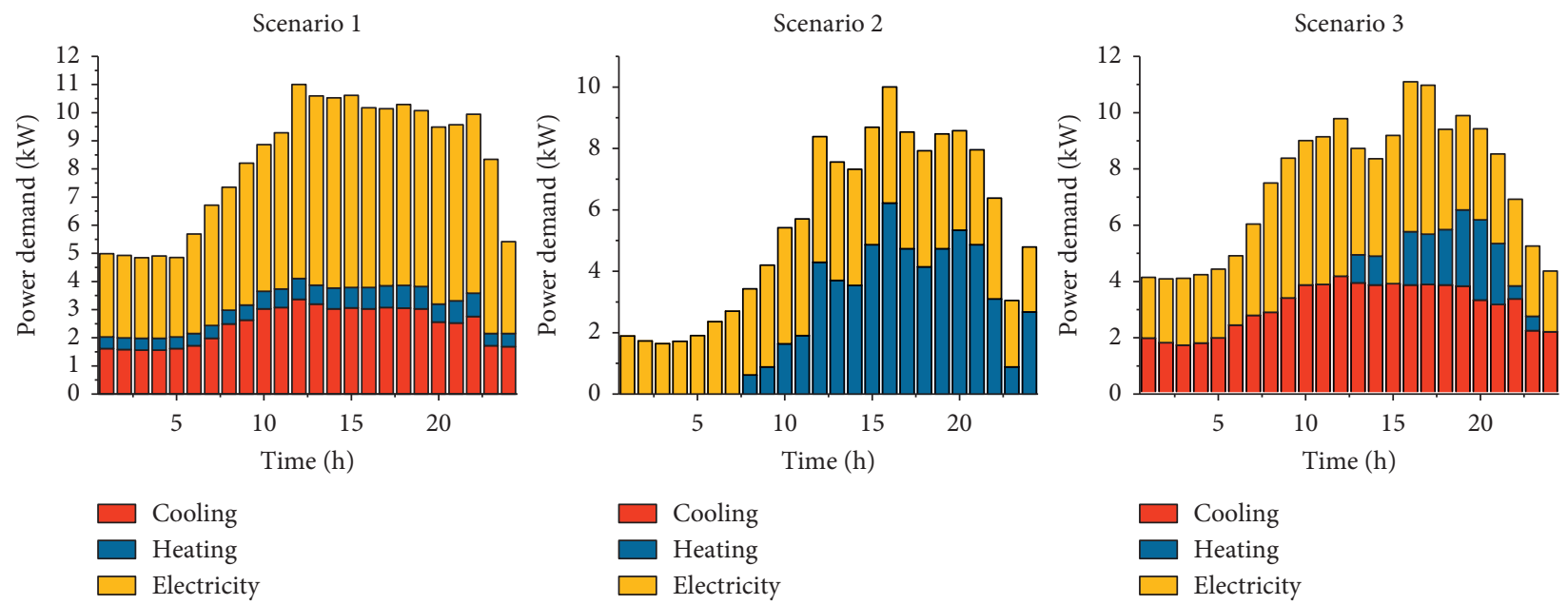

FIGURE 8: System energy supply information of scenarios 1-3 (designed for summer load).
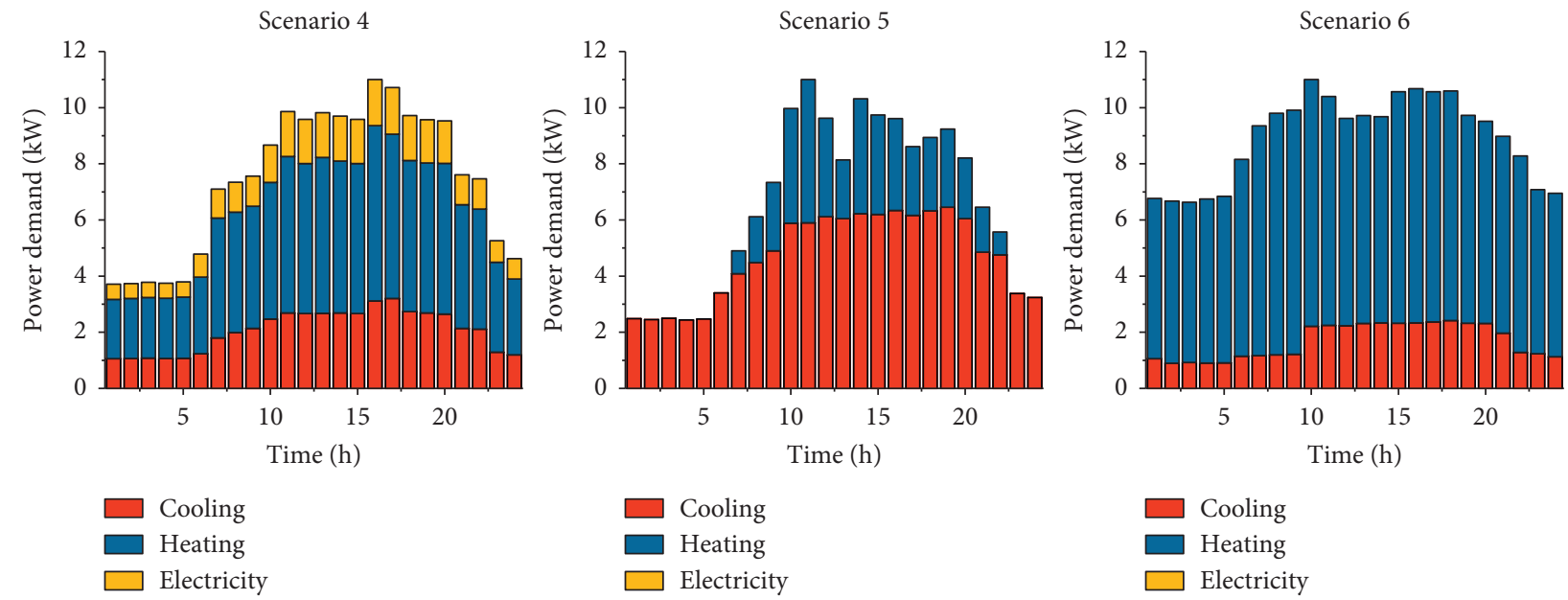

FIgURE 9: System energy supply information of scenarios 4-6 (designed for winter load).

TABle 6: Optimisation results summary table.

\begin{tabular}{|c|c|c|c|c|c|c|}
\hline Scenarios & Scenario 1 & Scenario 2 & Scenario 3 & Scenario 4 & Scenario 5 & Scenario 6 \\
\hline Electrical energy demand (kWh) & 58.92 & 93.47 & 72.21 & 49.49 & 113.14 & 40.461 \\
\hline Heat demand (kWh) & 14.44 & 0 & 16.35 & 101.22 & 43 & 173.77 \\
\hline Cooling demand $(\mathrm{kWh})$ & 123.42 & 55.46 & 87.13 & 27.56 & 0 & 0 \\
\hline Electrical energy generated by the engine ( $\mathrm{kWh}$ ) & 68.87 & 52 & 61.49 & 62.4 & 58.73 & 74.95 \\
\hline Energy supplied by electrical energy storage (kWh) & 20.04 & 24.3 & 37.48 & 27.04 & 46.8 & 12.61 \\
\hline Energy supplied by the heating storage unit (kwh) & 38.52 & 10.6 & 0.99 & 47.31 & 9.46 & 0 \\
\hline Energy supplied by the ORC system (kWh) & 4.48 & 3.37 & 4 & 4.06 & 3.56 & 4.88 \\
\hline System capacity enhancement (\%) & 63 & 47.01 & 64.61 & 55.10 & 41.50 & 64.15 \\
\hline Engine operation time $(\mathrm{h})$ & 10.55 & 8 & 9.46 & 9.6 & 8.41 & 11.53 \\
\hline Energy consumption amount (kWh) & 196.79 & 148.93 & 175.7 & 178.28 & 156.13 & 214.23 \\
\hline Overall efficiency (\%) & 33.49 & 36.13 & 34.92 & 49.51 & 43.7 & 56.53 \\
\hline Efficiency enhancement (\%) & 3 & 3.18 & 2.85 & 17.11 & 8.98 & 22.35 \\
\hline
\end{tabular}

\section{Conclusions}

This study describes a detailed study on the optimisation of the operation of the integrated CCHP system.

In the first case study, the proposed system supplied the complex power demand with the overall efficiency $35.70 \%$ and $42.70 \%$. There is over $40 \%$ efficiency enhancement compared to conventional separate production systems. Besides that, in the simulations, the optimisation process saves $3.61 \mathrm{kWh}$ and $1.86 \mathrm{kWh}$ in the summer case load and winter case load, respectively, compared to the original control strategy applied. 
In the second case study, several designed scenarios of loads are the power demand in the evaluation process of the system. The loads show a random energy consumption on typical summer days and on typical winter days. The overall efficiency varies from $33.49 \%$ to $56.53 \%$ in the 6 scenarios. The simulation of supplying the designed load and processing the optimisation on the system shows that the system's energy performance is enhanced from 3\% to $22.35 \%$.

This study shows that the idea of this integrated system is an efficient solution of multienergy products generation. Although this structure of the energy system has the ability of handling the dynamic power supplying with flexibility, more energy source is suggested in the future research.

\subsection{Future Work of This Project}

(1) As an off-grid energy system, the wind turbine, and the photovoltaic panel have great potential to supply green energy to the new designed CCHP system. More energy sources are looking forward to being integrated in.

(2) A more detailed thermal dynamic analysis about the system's thermal energy supplying will be carried on in the future work.

(3) The control strategy of the system has potential to be improved. In the future work, the intelligent algorithm will be added in for more flexible and efficient energy distribution.

\section{Nomenclature}

$P_{\text {fuel }}: \quad$ Fuel consumption (primary energy consumption) of the trigeneration system

$P_{\text {engine }}:$ Power output of the engine generator

$P_{s}: \quad$ Power output of the energy storage system

$P_{\mathrm{SU}}$ : $\quad$ Power output of the supercapacitor

$P_{\mathrm{BT}}: \quad$ Power output of batteries

$P_{\mathrm{LOAD}}$ : Electrical power demand (load)

$P_{R}: \quad$ Power output of the recovery system

$P_{T-\mathrm{ST}}$ : Power output of the thermal storage system

$P_{\mathrm{ET}}$ : $\quad$ Power consumption of transferring from electricity to thermal energy

$P_{\mathrm{EC}}$ : $\quad$ Power consumption of cooling generated by electricity

$P_{\mathrm{OE}}: \quad$ Power generated from the ORC system

$P_{\mathrm{OT}}: \quad$ Rate of low level heat from the ORC

$P_{\mathrm{ORC}}$ : Power output of the ORC system

$P_{C-L}: \quad$ Cooling load

$P: \quad$ Electrical output power

SOC: Batteries' state of charge

te: At the end of operation time

$C_{S}: \quad$ Batteries' capacity

$W_{p}$ : $\quad$ Power of the pump

$\xi: \quad$ Evaporator effectiveness

$Q_{\mathrm{ep}}: \quad$ Heat obtained by the evaporator

$Q_{\mathrm{ro}}: \quad$ Recovered thermal energy

E: $\quad$ Generated Electromotive Force (EMF) in volts $\varphi: \quad$ Air gap flux per pole in webers

$\Omega: \quad$ Angular velocity in radians per second

$T_{d}: \quad$ Developed torque in Newton-meters

$T_{d}: \quad$ Armature current in amperes

$K$ : $\quad$ Constant for the given machine

$\eta: \quad$ Electrical efficiency of the engine

$\eta_{C}$ : $\quad$ Efficiency of recovery heat transferring to cooling energy

$\eta_{p}: \quad$ Efficiency of the pump

$\eta_{\text {engine }}:$ Efficiency of the engine

$\eta_{\text {recovery }}$ : Efficiency of the recovery process

$\eta_{\text {ORC }}$ : Efficiency of the ORC

$\alpha: \quad$ Ratio of recovery heat transferring to thermal load supplying

$\beta$ : $\quad$ Ratio of recovery heat transferring to cooling supplying

$\sigma: \quad$ Self-discharge rate of the battery

$\eta_{\text {Bat }}: \quad$ Electricity efficiency of the battery

$\varepsilon: \quad$ Dielectric constant

E: $\quad$ The electric field intensity

C: $\quad$ Volume of the supercapacitor

$t^{\prime}: \quad$ Optimised

$m_{\text {ORC }}$ : Organic fluid mass flow rate

$W_{t}: \quad$ Turbine output power.

\section{Data Availability}

The data used to support the findings of this study are available from the corresponding author upon request.

\section{Conflicts of Interest}

The authors declare that they have no conflicts of interest.

\section{Acknowledgments}

The authors gratefully acknowledge the support by EPSRC Global Secure (EP/K004689/1) and National Natural Science Foundation of China (NSFC) (No.51709121).

\section{References}

[1] S. Yang, M. Liu, and F. Fang, State-of-the-Art of Combined Cooling, Heating, and Power (CCHP) Systems, John Wiley \& Sons, Ltd, Hoboken, NJ, USA, 2017.

[2] L. Grazia, "An innovative trigeneration system using the biogas as renewable energy," Chinese Journal of Chemical Engineering, vol. 26, no. 5, pp. 1179-1191, 2018.

[3] M. Ebrahimi and A. Keshavarz, "Climate impact on the prime mover size and design of a CCHP system for the residential building," Energy \& Buildings, vol. 54, pp. 283-289, 2012.

[4] S. Sanaye and A. Sarrafi, "Optimization of combined cooling, heating and power generation by a solar system," Renewable Energy, vol. 80, pp. 699-712, 2015.

[5] G. Abdollahi and M. Meratizaman, "Multi-objective approach in thermoenvironomic optimization of a small-scale distributed CCHP system with risk analysis," Energy and Buildings, vol. 43, no. 11, pp. 3144-3153, 2011.

[6] D. Maraver, "Assessment of CCHP systems based on biomass combustion for small-scale applications through a review of 
the technology and analysis of energy efficiency parameters," Applied Energy, vol. 102, pp. 1303-1313, 2013.

[7] F. Fang, Q. H. Wang, and Y. Shi, "A novel optimal operational strategy for the CCHP system based on two operating modes," IEEE Transactions on Power Systems, vol. 27, no. 2, pp. 1032-1041, 2011.

[8] W. Liu, "Hourly operation strategy of a CCHP system with GSHP and thermal energy storage (TES) under variable loads: a case study," Energy \& Buildings, vol. 93, pp. 143-153, 2015.

[9] Y. Li, "An optimal planning method for CCHP systems based on operation simulation," in Proceedings of the 2018 IEEE International Conference on Smart Energy Grid Engineering (SEGE), IEEE, Oshawa, Canada, August 2018.

[10] G. Yang, C. Y. Zheng, and X. Q. Zhai, "Influence analysis of building energy demands on the optimal design and performance of CCHP system by using statistical analysis," Energy \& Buildings, vol. 153, pp. 297-316, 2017.

[11] C. Yang, "Design and simulation of gas turbine-based CCHP combined with solar and compressed air energy storage in a hotel building," Energy \& Buildings, vol. 153, pp. 412-420, 2017.

[12] X.-P. Chen, Y.-D. Wang, and W. U. L Qin-Mu, "A bio-fuel power generation system with hybrid energy storage under a dynamic programming operation strategy," IEEE Access, vol. 7, pp. 64966-64977, 2019.

[13] L. Urbanucci, F. D’Ettorre, and D. Testi, “A comprehensive methodology for the integrated optimal sizing and operation of cogeneration systems with thermal energy storage," Energies, vol. 12, no. 5, p. 875, 2019.

[14] Y. Wang, F. Ronilaya, X. Chen, and A. P. Roskilly, "Modelling and simulation of a distributed power generation system with energy storage to meet dynamic household electricity demand," Applied Thermal Engineering, vol. 50, no. 1, pp. 523-535, 2013.

[15] W. Lang, "Feasibility analysis of CCHP system with thermal energy storage driven by micro turbine," Energy Procedia, vol. 105, pp. 2396-2402, 2017.

[16] A. H. Nosrat, L. G. Swan, and J. M. Pearce, "Improved performance of hybrid photovoltaic-trigeneration systems over photovoltaic-cogen systems including effects of battery storage," Energy, vol. 49, pp. 366-374, 2013.

[17] J. . Í. Libich, "Supercapacitors: properties and applications," Journal of Energy Storage, vol. 17, pp. 224-227, 2018.

[18] X. P. Chen, N. Hewitt, Z. T. Li, Q. M. Wu, X. Yuan, and T. Roskilly, "Dynamic programming for optimal operation of a biofuel micro CHP-HES system," Applied Energy, vol. 208, pp. 132-141, 2017.

[19] F. Fang, "Complementary configuration and operation of a CCHP-ORC system," Energy, vol. 46, no. 1, pp. 211-220, 2012.

[20] A. Mohammadi and M. Mehrpooya, "Energy and exergy analyses of a combined desalination and CCHP system driven by geothermal energy," Applied Thermal Engineering, vol. 116, pp. 685-694, 2017.

[21] A. Sadreddini, "Exergy analysis and optimization of a CCHP system composed of compressed air energy storage system and ORC cycle," Energy Conversion \& Management, vol. 157, pp. 111-122, 2018.

[22] V. Zare and H. Rostamnejad Takleh, "Novel geothermal driven CCHP systems integrating ejector transcritical $\mathrm{CO} 2$ and Rankine cycles: thermodynamic modeling and parametric study," Energy Conversion and Management, vol. 205, Article ID 112396, 2020.

[23] S. Wang and Z. Fu, "Thermodynamic and economic analysis of solar assisted CCHP-ORC system with DME as fuel,"
Energy Conversion and Management, vol. 186, pp. 535-545, 2019.

[24] Y. Zhu, W. Li, and G. Sun, "Thermodynamic analysis of evaporation temperature glide of zeotropic mixtures on the ORC-CCHP system integrated with ejector and heat pump," Energy Procedia, vol. 158, pp. 1632-1639, 2019.

[25] P. J. Mago, N. Fumo, and L. M. Chamra, "Performance analysis of CCHP and CHP systems operating following the thermal and electric load," International Journal of Energy Research, vol. 33, no. 9, pp. 852-864, 2009.

[26] J. Ji, C. He, Z. Xiao et al., "Simulation study of an ORC system driven by the waste heat recovered from a trigeneration system," Energy Procedia, vol. 105, pp. 5040-5047, 2017.

[27] Y. Hong Dong, W. Yao Dang, W. Da, T. Roskilly, H. S. Chen, and C. Q. Tan, "Performance of a micro-cogeneration system running with preheated raw vegetable oils," Applied Mechanics and Materials, vol. 453, p. 6, 2013.

[28] E. Galloni, G. Fontana, and S. Staccone, "Design and experimental analysis of a mini ORC (organic Rankine cycle) power plant based on R245fa working fluid," Energy, vol. 90, pp. 768-775, 2015.

[29] L. Luo, Y. Wang, H. Chen, X. Zhang, and T. Roskilly, "ORC units driven by engine waste heat-a simulation study," Energy Procedia, vol. 142, pp. 1022-1027, 2017.

[30] F. Tsang, "What works in changing energy-using behaviours in the home?" Final Report, A Rapid Evidence Assessment, London, UK, 2012. 